\title{
ACL injury in football: a literature overview of the prevention programs
}

\author{
Gian Nicola Bisciotti ${ }^{1}$ \\ Karim Chamari ${ }^{1}$ \\ Emanuele Cena ${ }^{1}$ \\ Giulia Carimati ${ }^{2}$ \\ Piero Volpi $\mathbf{i}^{2,3}$ \\ 1 Qatar Orthopaedic and Sport Medicine Hospital, \\ FIFA Center of Excellence, Doha, Qatar \\ 2 Department of Knee Orthopedic and Sports \\ Traumatology Unit, Humanitas Research Hospital. \\ Rozzano (MI), Italy \\ ${ }^{3}$ FC Internazionale Medical Staff. Milano, Italy
}

\section{Corresponding author:}

Piero Volpi

Department of Knee Orthopaedic and Sports

Traumatology Unit, Humanitas Research Hospital

Via Manzoni 56

20089 Rozzano (MI), Italy

E-mail: volpi.piero@libero.it

\section{Summary}

Background: The ACL prevention programs are addressed to the control and/or modification of the so-called "modifiable risk factors". All these programs focus on different intervention strategies aimed to decrease the ACL injury risk, particularly in female athletes population.

Purpose: To furnish an overview of the most used $A C L$ injury prevention program through a narrative review.

Conclusion: In literature there are many reports on prevention programs whose common denominator is the proper alignment of the lower limb joints and proper motor control during movements that are considered at risk for ACL integrity, as the landing phase after a jump. Nevertheless, some programs would appear more effective than others. In any cases a major problem remains the lack of sufficient compliance in respect of prevention programs. Finally, it is important to remember that the ethiology of $A C L$ injuries is multifactorial. For this reason a prevention program able to prevent all the risk situations is utopian.

Study design: Narrative review.
KEY WORDS: compliance, modifiable risk factors, prevention programs.

\section{Introduction}

In football one of the most dramatic events that may occur is the rupture of the anterior cruciate ligament (ACL). Some studies report that the incidence of severe knee sprains involving the ACL injury is, in football, equal to 0.063 events per 1.000 hours of exposure time ${ }^{1}$. The ACL injury risk is higher, during the competition rather than in training ${ }^{2-4}$. Unfortunately the ACL rupture may affect the footballer's career 5 . Indeed the return to play calculated 12 months after ACL reconstruction in some studies is only equal to $33 \% 5$. Furthermore, it is important to underline the relatively high risk of re-injury (between 4 and 13\%) reported by several Authors ${ }^{6-9}$. For all this reason the importance of $\mathrm{ACL}$ prevention programs in modern football is paramount. The purpose of this narrative review, conducted in according to international standards ${ }^{10}$ is to give an overview concerning the problematic of prevention program for ACL injuries in football.

\section{The rationale of prevention programs}

Prevention of ACL lesion is a major priority as return to sport at the same pre-injury level after ACL injury is around $55 \%{ }^{11}$. Furthermore, it is important to remember that an ACL lesion means the risk of the development of a post-traumatic osteoarthritis $(\mathrm{OA})^{12,13}$. Since excessive valgus stress is one of the major risk factors regarding the $A C L$ anatomical integrity, the motor control of all movements that can cause an excessive dynamic valgus, is a key part of prevention programs ${ }^{14,15}$. Although at that time in the literature do not exist standardized programs focused on noncontact ACL injuries. Alentorn-Geli et al. ${ }^{16,17}$ concluded in a review study showing that the so called "multicomponent programs" were more effective than the "single-component programs" in ACL prevention. The Authors concluded that, in general, all the programs based on neuromuscular training (i.e. plyometric exercises, dynamic balance training, muscle strengthening, stretching, increase in body control, control of impact forces during landing after a jump, control of the valgus and varus stresses and increase of muscle 
activation) were effective for ACL injury prevention, especially for the female population. The same conclusions, concerning the effectiveness of the programs focused on neuromuscular training, were made by other several Authors ${ }^{18-20}$. On the contrary, in a systematic review, Grimm et al. ${ }^{21}$ focused on ACL and knee injury prevention program in general showed a statistically significant reduction in injury risk for knee injuries but did not find a statistically significant reduction of $A C L$ injuries. This demonstrates the low specificity of the considered programs. In any case, the effectiveness of the prevention programs focused on neuromuscular training is probably based on the improvement in motor control skill based on the plasticity of the $\mathrm{SNC}^{22}$. SNC plasticity may produce a change in corticomotor excitability related to motor experience 23 . These corticomotor changes (in terms of decreased excitability) reflect a supraspinal adaptation in response to neuromuscular training 24 .

Soligard et al. ${ }^{25}$ validated the effectiveness of a warm-up standardized program applied on a population of 1892 footballers belonging to 125 Norwegian clubs (1055 belonging to the study group and 837 to the control group) aged between 13 and 17 years. The program showed its effectiveness in decreasing the lesions at lower limbs level. La Bella et al. ${ }^{26}$ conducted a similar study to the above mentioned study validating the effectiveness of a "neuromuscular warm-up" concerning injuries prevention at lower limbs level. The program was conducted in a population of 1492 female subjects. More recently Walden et al. ${ }^{27}$ demonstrated the positive effect of a muscle training program in preventing ACL injuries in a female footballers population composed by 4564 subjects (2479 belonging to the study group and 2085 to the control group) aged between 12 and 17 years. It is however difficult to indicate exactly the exercises, the workload and the frequency on which these prevention programs have been based due to lack of clear explanations in the published articles ${ }^{28}$. It is likely that only the balance and proprioceptive exercises, especially if carried out without external supervision, are not effective for this purpose and therefore it is necessary to add to these programs specific strengthening exercises for the lower limbs muscles, core stability training and specific exercises focused on improving the post-jump landing skills ${ }^{29,30}$.

\section{The compliance challenge}

A further, and not underestimated difficulty is the compliance demonstrated by the athletes for injuries prevention program. Indeed, two questions should be considered: "How many times per week the adopted prevention program must be performed in order to hope for its effectiveness?", and "How many times is reasonable and realistic to perform the prevention program in the weekly training plans without finding resistance/reluctance and difficulties by coaches, managers and players?" In an 8-year span project
(Football Excellence Project, the study involved 22 teams over 3 seasons, in Qatar Football Association, managed by Aspetar, Doha, Qatar), the prevention program adopted (namely the FIFA 11+) was applied on average for $35 \%$ of the total training sessions ${ }^{31}$.

FIFA $11+$ program is a warm-up program designed to prevent injuries and combines a series of exercises that aims to provide general protection from injuries. It is recommended that the " $11+$ " is performed prior to every training session. FIFA suggests that players should be at least 14 years of age to start it ${ }^{32}$.

Only in the case in which FIFA $11+$ program is performed during at least $75 \%$ of sessions of football exposure (training sessions and matches) it could be an effective preventive tool in musculoskeletal lower limbs injuries in young male footballers. Its positive effects are lost if the percentage is lower than 75\%33-35.

Several Authors have raised the issue of lack of compliance for prevention programs ${ }^{17,33,34,36}$. Reasons for low compliance may include:

i. Requirements of a specific warm-up for an equally specific type of training session

ii. Boredom of players to perform always the same type of warm-up

iii. Specific needs of the coach and/or of the physical trainer.

In this context, the application of a prevention program (albeit of limited duration, i.e. 15-20 minutes as in the case FIFA 11+ prevention program) collides with the needs and practical limitations of daily field reality ${ }^{31}$

The same problem of lack of compliance is present in ACL prevention programs. Thein-Nissenbaum and Brooks $^{37}$ showed that a population of female high school basketball players demonstrated very low compliance with a home-based ACL injury prevention program. The Authors identified as main barrier a lack of compliance with the lack of time justifying $80 \%$ of the lack of compliance. Other reasons for a lack of compliance were that the participants simply forgot to perform the program and/or that the exercise program was too long, although each program was approximately of only 15 minutes in length. The last barrier reported was the boredom that subjects felt during the prevention program sessions.

Olsen et al. ${ }^{38}$ in a study focusing on the effect of a structured warm-up programme designed to reduce the incidence of knee and ankle injuries in young athletes, have demonstrated similar findings of lack of compliance.

Pfeiffer et al. ${ }^{39}$ conducted a study in high-school female athletes (playing soccer, basketball, and volleyball) from fifteen schools (112 teams) for two consecutive seasons. The study focused on a knee ligament injury prevention program based on plyometric-based exercise performed twice a week throughout the season. The result of the study showed that the low number of weekly prevention training sessions and the lack of compliance caused that the program did not reduce the rate of non-contact anterior cruciate ligament injuries.

Since several meta-analysis studies ${ }^{40,41}$ reported that 
higher compliance rates with prevention programs was associated with lower rates of ACL injury incidence. It is therefore clear that the lack of compliance represents a serious problem for the effectiveness of $A C L$ injury prevention programs. For this reason it is paramount to identify barriers to programs' implementation and compliance and to create strategies to overcome the issues associated with a lack of compliance. Some issues linked with the lack of compliance are represented by the lack of time and space. For this reason it's very important that the prevention programs be implemented in a short, efficient manner requiring minimal equipment and space. Furthermore, the interventions must be tailored to an individual's needs. Finally is essential to reduce the boredom which is sometimes linked to sport-related injuries prevention program. In that regard, low levels of conflict, high levels of cohesion and organization, and good communication patterns in the teams are normally associated with good regimen of adherence ${ }^{42}$. A satisfactory level of adherence needs individualization and should take into account the patient's age, lifestyle, personal motivation, interests, and must use the right means of motivation ${ }^{43}$.

\section{The age at which to start the prevention pro- grams}

An important question is "when, in terms of chronological age, it is correct to begin to propose a prevention training". The answer is "soon". In other words, it seems correct to start a prevention training at 13 years, both for male and female population. In fact, although the risk of injuries is quite low under 12 years old 44,45 an early introduction of prevention exercises can promote a correct mindset and a habit to this type of training. ACL injuries are being seen with a greater frequency in the paediatric population ${ }^{46}$. $\mathrm{ACL}$ injury risk begins to increase significantly at 12 to 13 years old in girls and at 14 to 15 years of age in boys 47,48 . Although, in literature we can find sport-related $\mathrm{ACL}$ injuries in children as young as 5 years, the data concerning $A C L$ disruptions in children younger than 12 years are rare ${ }^{47-50}$. In any case, an early introduction of training prevention will make into adulthood easier to obtain a good compliance for such type of training. It is important to underline an interesting meta-analysis study ${ }^{51}$ that showed an agerelated association between prevention neuromuscular training implementation and reduction of ACL incidence in a female population. In this study biomechanical and epidemiological data demonstrated that the potential window of opportunity for optimized neuromuscular training, and consequently ACL injury risk reduction, may be before the onset of neuromuscular deficits and peak knee injury incidence in female athletes. In that regard, it has to be remembered that in female athletes, ACL sports-related injuries increase during adolescence and the incidence peak is during the mid- to late teens ${ }^{51}$. Again as part of the prevention of ACL injuries in pre-adolescents and adoles- cent athletes, some studies demonstrate that integrative neuromuscular training protocols can reduce the risk of sports-related injury in young athlete ${ }^{52-54}$. Ladenhauf et al. ${ }^{55}$ recommend that young athletes should perform, especially in preseason period, training programs focused on strengthening, neuromuscular and proprioceptive exercises under appropriate supervision of qualified personnel. However, Noyes and Barber-Westin8 in their review study focused on ACL injuries prevention in female athletes under the age of 19 years, showing that only three studies (over the eight considered studies) effectively reduced noncontact ACL injury rate. The Authors concluded that pooling of data of all ACL intervention programs is not recommended because of numerous methodological differences among studies. Based on previous research 55,56 , it could be concluded that unfortunately, the level of evidence regarding the prevention of $\mathrm{ACL}$ injuries in young athletes is quite variable and also if there has been considerable research to test preventive measures for ACL injury, the problem still need more evidence-based studies.

\section{Hewett's four hypothesis}

Returning to the exposed theories by Hewett et al. ${ }^{57}$, already discussed in the previous paper ( $A C L$ injury in football: risk factors) the first hypothesis (i.e. the ligament dominance hypothesis) provides the introduction of specific training for proper technique especially concerning the landing phase. In the literature, five studies focused on the investigation of the biomechanical variables associated with the ligament dominance hypothesis ${ }^{58-62}$. The results of these studies were variable. In one study ${ }^{49}$ focusing on male athletes, the subjects showed positive effects after the injury prevention programme reducing the knee valgus moment. However, this specific risk factor has to date been identified only in female population ${ }^{63}$. On the contrary, the other studies showed no substantial benefits on variables related to the ligament dominance hypothesis. In effect, these studies reported only some isolated positive effects and therefore require further investigations. In any case, in summary, the prevention programmes related to the ligament dominance hypothesis seem to be promising in adult athletes.

Regarding the interventions addressed to the second hypothesis (i.e. the quadriceps dominance) these latter must be focused on influencing the athletes - especially the women - to be less "quadriceps dominant" emphasizing the hamstring recruitment. So far, two studies has been published reporting positive electromyography changes which are considered to reduce the risk of $A C L$ injury by increasing hamstrings strength particularly the medial hamstring 64,65 and decreasing at the same time the quadriceps electromyographyc activity ${ }^{55}$. In another study Cochrane et al. ${ }^{66}$ reported that in a population of experienced team sport athletes, after an injury prevention programme, at initial foot contact, the subjects 
placed their stance foot closer to the body's midline and held their torso more upright. These results were in line with the aims of the technique modification training. The Authors concluded that these results were indicative of decreased exposure to ACL risk. However, the fact that the effect size of the difference could not be assessed due to the lack of descriptive statistics, further studies need to make more robust conclusions concerning this second hypothesis.

Concerning the third hypothesis (i.e. the leg dominance hypothesis) the specific programs are based on single leg balance and single leg hopping techniques. Indeed, although it may seem counter-intuitive, the more single leg activities an athlete performs, the more side to side symmetry is restored ${ }^{57}$. Unfortunately, there are, to the best of the Authors' knowledge, no studies about prevention programs based on any variables associated to the leg-dominance hypothesis.

Regarding the last hypothesis formulated by Hewett et al. ${ }^{57}$ (i.e. the trunk dominance hypothesis) the prevention programs are based on core training. The programs must focus on core training with specific instruction in activities providing stability by transversus abdominis, multifidus and pelvic/hip stabilizers ${ }^{47}$. To our knowledge, currently only one study investigated the effect of an injury prevention programme based on trunk biomechanics ${ }^{59}$. The results of this study showed a decreasing in lateral flexion angle at initial contact of post-jump landing phase after training. Since a lateral trunk displacement after a sudden release task is a predictor of ACL injury ${ }^{57}$, this represents an important finding. However, since only one study in literature demonstrates the beneficial effect of injury prevention programmes on trunk dominance variables it is currently difficult to make robust conclusions and future studies need to confirm this hypothesis.

In conclusion, literature ${ }^{16,17,67-70}$, suggests that data regarding the effectiveness of prevention programmes to reduce $A C L$ injuries or to modify ACL injuries risk factors are not conclusive, even though some interesting findings already helped practitioners to orientate their practice. Future researches focusing on detection of the most effective approaches to optimize the efficacy of prevention programmes in reducing ACL injuries in athletes are necessary.

\section{The use of bracing}

The use of bracing can be considered as a mean of prevention after an initial partial ACL injury, and in order to avoid a total rupture. However, the literature suggests that is would be unlikely that bracing use could decrease the risk of ACL re-injury. Wojtys et al. ${ }^{71}$ studied the effects of 6 different brace designs on anterior tibial translation and neuromuscular function in chronically unstable ACL-deficient patients. Results show that braces decrease anterior tibial translation in a range of 28.8 to $39.1 \%$ also without the stabilizing contractions of the hamstring, quadri- ceps, and gastrocnemius muscles. With lower extremity muscles activation in addition to bracing, anterior tibial translation was decreased by 69.8 to $84.9 \%$. However, an important problem was represented by the fact that the bracing consistently slowed hamstring muscle reaction times at the voluntary level. In another study ${ }^{72}$ focusing on the use of bracing and conducted on one hundred volunteers from the 3 US service academies with acute anterior cruciate ligament tears, the results showed that the use of bracing is expensive and is not proven to prevent injuries or influence outcomes. Furthermore, the use of bracing not only does not improve functional performance after ACL partial lesion but may also reduce running and turning speed ${ }^{73}$. Knee braces studies about the athletes comfort and/or reluctance to use braces are lacking. Indeed, depending on the sport practiced and the athlete, using braces during training and/or matches could raise reluctance and discomfort.

\section{Future directions}

Given the importance of hamstring contraction into the control of anterior tibia shift it is paramount to implement the existing ACL injury prevention program with specific part dedicated to hamstring neuromuscular control.

Within the design of an ACL injury prevention program, it is important to consider the differences in injury mechanisms especially concerning the different risk factors existing in male and female population. For example, in female ACL prevention program there should be a greater focus on dynamic trunk training than in a program developed for male athletic population.

Since neuromuscular control may be the most important and most modifiable factor in ACL prevention, maximum efforts should be made to develop and improve these types of programs. This is paramount especially in female and adolescent athletes population where neuromuscular training appears very effective to reduce the risk of ACL injury.

Finally it seems important to adopt effective strategies to increase compliance for ACL injury prevention programs in athletes.

\section{Conclusions}

Considering the disabling consequences, especially in case of athletic subjects, and high costs caused by ACL injuries, the importance for the prevention is of paramount importance. In any case, since the ethiology of ACL injury is multifactorial, a total prevention is simply impossible. Especially the ACL contact injuries are completely unpredictable and therefore most probably cannot take advantage from a prevention program. Nevertheless, the more effective prevention programs seem to be the so-called "multi-component 
programs". A common point for all these types of programs is represented by the importance given to the proper alignment of the hip, knee and ankle joints during the cutting exercises, change of direction and post-jump landing. For any type of prevention program, the problems concerning the correct workload, the training frequency, and the compliance by the athlete still remains.

\section{Conflicts of interest}

The Authors declare no conflicts of interest concerning this article.

\section{References}

1. Bjordal JM, Arnły F, Hannestad B, Strand T. Epidemiology of anterior cruciate ligament injuries in soccer. Am J Sports Med. 1997;25(3):341-345.

2. Giza E, Mithöfer K, Farrell L, Zarins B, Gill T. Injuries in women's professional soccer. Br J Sports Med. 2005;39(4):212216.

3. Alentorn-Geli E, Myer GD, Silvers HJ Samitier G, Romero D, Lázaro-Haro C, Cugat R. Prevention of non-contact anterior cruciate ligament injuries in soccer players. Part 2: a review of prevention programs aimed to modify risk factors and to reduce injury rates. Knee Surg Sports Traumatol Arthrosc. 2009 17(8):859-879.

4. Waldén $\mathrm{M}$, Hägglund $\mathrm{M}$, Magnusson $\mathrm{H}$, Ekstrand $\mathrm{J}$. Anterior cruciate ligament injury in elite football: a prospective three-cohort study. Knee Surg Sports Traumatol Arthrosc. 2011;19 (1):11-19.

5. Ardern CL1, Taylor NF, Feller JA, Whitehead TS, Webster KE. Psychological responses matter in returning to preinjury leve of sport after anterior cruciate ligament reconstruction surgery. Am J Sports Med. 2013;41(7):1549-1558.

6. Paterno MV, Schmitt LC, Ford KR, Rauh MJ, Myer GD, Huang $B$, Hewett TE. Biomechanical measures during landing and postural stability predict second anterior cruciate ligament injury after anterior cruciate ligament reconstruction and return to sport. Am J Sports Med. 2010;38(10):1968-1978.

7. Myer GD, Martin L Jr, Ford KR, et al. No association of time from surgery with functional deficits in athletes after anterior cruciate ligament reconstruction: evidence for objective returnto-sport criteria. Am J Sports Med. 2012;40(10):2256-2263.

8. Myer GD, Sugimoto D, Thomas S, Hewett TE. The influence of age on the effectiveness of neuromuscular training to reduce anterior cruciate ligament injury in female athletes: a metaanalysis. Am J Sports Med. 2013;41(1):203-215.

9. Paterno MV, Rauh MJ, Schmitt LC, Ford KR, Hewett TE. Incidence of Second ACL Injuries 2 Years After Primary ACL Reconstruction and Return to Sport. Am J Sports Med. 2014;42 (7):1567-1573

10. Padulo J, Oliva F, Frizziero A, Maffulli N. Muscles, Ligaments and Tendons Journal - Basic principles and recommendations in clinical and field Science Research: 2016 Update. MLTJ. 2016;6(1):1-5.

11. Ardern CL, Taylor NF, Feller JA, et al. Fifty-five per cent return to competitive sport following anterior cruciate ligament reconstruction surgery: an updated systematic review and metaanalysis including aspects of physical functioning and contextual factors. Br J Sports Med. 2014;48:1543-1552.

12. Lohmander LS, Englund PM, Dahl LL, et al. The long-term consequence of anterior cruciate ligament and meniscus in- juries: osteoarthritis. Am J Sports Med. 2007;35:1756-1769.

13. Oiestad BE, Holm I, Aune AK, et al. Knee function and prevalence of knee osteoarthritis after anterior cruciate ligament reconstruction. Am J Sports Med. 2010;38:2201-2210.

14. Olsen OE, Myklebust G, Engebretsen L, Bahr R. Injury mechanisms for anterior cruciate ligament injuries in team handball: a systematic video analysis. Am J Sports Med. 2004;32(4): 1002-1012.

15. Koga $H$, Nakamae A, Shima $Y$, et al. Mechanisms for noncontact anterior cruciate ligament injuries: knee joint kinematics in 10 injury situations from female team handball and basketball. Am J Sports Med. 2010;38(11):2218-2225.

16. Alentorn-Geli E, Myer GD, Silvers HJ, Samitier G, Romero D, Lázaro-Haro C, Cugat R. Prevention of non-contact anterior cruciate ligament injuries in soccer players. Part 1: Mechanisms of injury and underlying risk factors. Knee Surg Sports Traumatol Arthrosc. 2009;17(7):705-729.

17. Alentorn-Geli E, Myer GD, Silvers HJ, Samitier G, Romero D, Lázaro-Haro $\mathrm{C}$, Cugat R. Prevention of non-contact anterior cruciate ligament injuries in soccer players. Part 2: a review of prevention programs aimed to modify risk factors and to reduce injury rates. Knee Surg Sports Traumatol Arthrosc. 2009;17(8):859-879.

18. Noyes FR, Barber-Westin SD. Neuromuscular retraining intervention programs: do they reduce noncontact anterior cruciate ligament injury rates in adolescent females? Arthroscopy. 2014;30:245-255.

19. Stevenson JH, Beattie CS, Schwartz JB, Busconi BD. Assessing the effectiveness of neuromuscular training programs in reducing the incidence of anterior cruciate ligament injuries in female athletes: a systematic review. Am J Sports Med. 2015;43(2):482-490.

20. Sugimoto D, Myer GD, Foss KD, Hewett TE. Specific exercise effects of preventive neuromuscular training intervention on anterior cruciate ligament injury risk reduction in young females: meta-analysis and subgroup analysis. $\mathrm{Br} \mathrm{J}$ Sports Med. 2015;49(5):282-289.

21. Grimm NL, Jacobs JC Jr, Kim J, Denney BS, Shea KG. Anterior Cruciate Ligament and Knee Injury Prevention Programs for Soccer Players: A Systematic Review and Meta-analysis. Am J Sports Med. 2015;43(8):2049-2056.

22. Doyon J, Orban P, Barakat M, et al. Functional brain plasticity associated with motor learning. Med Sci (Paris). 2011;27(4) 413-420.

23. Jensen JL, Marstrand PC, Nielsen JB. Motor skill training and strength training are associated with different plastic changes in the central nervous system. J Appl Physiol. 2005;99(4) 1558-1568.

24. Schubert M, Beck S, Taube W, Amtage F, Faist M, Gruber M. Balance training and ballistic strength training are associated with task-specific corticospinal adaptations. Eur J Neurosci. 2008;27(8):2007-2018

25. Soligard T, Myklebust G, Steffen K, et al. Comprehensive warm-up programme to prevent injuries in young female footballers: cluster randomised controlled trial. BMJ. 2008;337: a2469.

26. LaBella CR, Huxford MR, Grissom J, Kim KY, Peng J, Christoffel KK. Effect of neuromuscular warm-up on injuries in female soccer and basketball athletes in urban public high schools: cluster randomized controlled trial. Arch Pediatr Adolesc Med. 2011;165(11):1033-1040.

27. Waldén $\mathrm{M}$, Atroshi I, Magnusson $\mathrm{H}$, Wagner $\mathrm{P}$, Hägglund $\mathrm{M}$. Prevention of acute knee injuries in adolescent female footbal players: cluster randomised controlled trial. BMJ. 2012;344: e3042.

28. Bien DP. Rationale and implementation of anterior cruciate ligament injury prevention warm-up programs in female athletes. J Strength Cond Res. 2011;25(1):271-285. 
29. Söderman K, Werner S, Pietilä T, Engström B, Alfredson H. Balance board training: prevention of traumatic injuries of the lower extremities in female soccer players? A prospective randomized intervention study. Knee Surg Sports Traumatol Arthrosc. 2000;8(6):356-363.

30. Engebretsen AH, Myklebust G, Holme I, Engebretsen L, Bahr R. Prevention of injuries among male soccer players: a prospective, randomized intervention study targeting players with previous injuries or reduced function. Am J Sports Med. 2008;36(6):1052-1060.

31. Bisciotti 2015 (unpublished data).

32. Bizzini M, Dvorak J. FIFA 11+: an effective programme to prevent football injuries in various player groups worldwide-a narrative review. Br J Sports Med. 2015;49(9):577-579.

33. Steffen K, Myklebust G, Olsen OE, Bahr R. Prevention injuries in female youth football- a cluster-randomized controlled trial. Scan J Med Sci Sport. 2008;18(5):605-614.

34. López JA, Palavicini C, Saldaña S, García HC, Aguilar CB. Analysis of the effectiveness of "The 11+" program to prevent musculoskeletal lower limbs injuries in young male footballers for the 2010-2011 national championship. In: Strength training for soccer. Swinnen B (Editors). Routledge (Ed), London, 2016.

35. Steffen K, Meeuwisse WH, Romiti M, et al. Evaluation of how different implementation strategies of an injury prevention programme (FIFA 11+) impact team adherence and injury risk in Canadian female youth football players: a cluster-randomised trial. Br J Sports Med. 2013;47(8):480-487.

36. Kilding AE, Tunstall H, Kuzmic D. Suitability of FIFA's "The 11" Training Programme for Young Football Players - Impact on Physical Performance. J Sports Sci Med. 2008;7(3):320-326.

37. Thein-Nissenbaum J, Brooks MA. Barriers to compliance in a home-based anterior cruciate ligament injury prevention program in female high school athletes. WMJ. 2016;115(1):37-42.

38. Olsen OE, Myklebust G, Engebretsen L, Holme I, Bahr R. Exercises to prevent lower limb injuries in youth sports: cluster randomised controlled trial. BMJ. 2005;330(7489):449.

39. Pfeiffer RP, Shea KG, Roberts D, Grandstrand S, Bond L. Lack of effect of a knee ligament injury prevention program on the incidence of noncontact anterior cruciate ligament injury. $J$ Bone Joint Surg Am. 2006;88(8):1769-1774.

40. Sugimoto D, Myer GD, Bush HM, et al. Compliance with neuromuscular training and anterior cruciate ligament injury risk reduction in female athletes: a meta-analysis. J Athl Train. 2012;47(6):714-723.

41. Sugimoto D, Myer GD, Foss KD, Hewett TE. Dosage effect of neuromuscular training intervention to reduce anterior cruciate ligament injuries in female athletes. Meta and meta sub-group analyses. Sports Med. 2014;4:551-562.

42. Delamater AM, Jacobson AM, Anderson B, et al. Psychosocial therapies in diabetes: report of the Psychosocial Therapies Working Group. Diabetes Care. 2001;24(7):1286-1292.

43. Vanelli M, Corchia M, lovane B, Bernardini A, Mele A, Chiari G. Self-monitoring adherence to physical activity in children and adolescents with type 1 diabetes. Acta Biomed. 2006;77(Suppl 1):47-50.

44. Froholdt A, Olsen OE, Bahr R. Low risk of injuries among children playing organized soccer: a prospective cohort study. Am J Sports Med. 2009;37(6):1155-1160.

45. Volpi P, Bisciotti GN. L'epidemiologia delle lesioni nel calcio giovanile. Med Sport. 2015;68(1):1-7.

46. Ladenhauf HN, Graziano J, Robert G, Marx RG. Anterior cruciate ligament prevention strategies: are they effective in young athletes - current concepts and review of literature. Curr Opin Pediatr. 2013;25:64-71.

47. Shea KG, Pfeiffer R, Wang JH, Curtin M, Apel PJ. Anterior cruciate ligament injury in pediatric and adolescent soccer players: an analysis of insurance data. J Pediatr Orthop. 2004;24 (6):623-628.

48. Granan LP, Forssblad M, Lind M, Engebretsen L. The Scandi- navian ACL registries 20042007: baseline epidemiology. Acta Orthop. 2009;80(5):563-567.

49. Renstrom $P$, Ljungqvist $A$, Arendt E, et al. Non-contact ACL injuries in female athletes: an International Olympic Committee current concepts statement. Br J Sports Med. 2008;42(6):394412.

50. Comstock R, Collins C, Mcllvain N. National High-School Sports-Related Injury Surveillance Study, 2009-2010 School Year Summary. Columbus, $\mathrm{OH}$ : The Research Institute at Nationwide Children's Hospital; 2010. Available at: www.nationwidechildrens.org/cirp-rio-study-reports. Accessed February 28, 2013.

51. Myer GD, Sugimoto D, Thomas S, Hewett TE. The influence of age on the effectiveness of neuromuscular training to reduce anterior cruciate ligament injury in female athletes: a metaanalyses. Am J Sports Med. 2013;41(1):203-215.

52. Hewett TE, Lindenfeld TN, Riccobene JV, Noyes FR. The effect of neuromuscular training on the incidence of knee injury in female athletes: A prospective study. Am J Sports Med. 1999;27:699-706.

53. Myer GD, Brunner HI, Melson PG, Paterno MY, Ford KR, Hewett TE. Specialized neuromuscular training to improve neuromuscular function and biomechanics in a patient with quiescent juvenile rheumatoid arthritis. Phys Ther. 2005; 85:791-802.

54. Myer GD, Ford KR, Hewett TE. The effects of gender on quadriceps muscle activation strategies during a maneuver that mimics a high ACL injury risk position. J Electromyogr Kinesiol. 2005;15(2):181-189.

55. Ladenhauf HN, Graziano J, Marx RJ. Anterior cruciate ligament prevention strategies: are they effective in young athletes-current concepts and review of literature. Curr Opin Pediatr. 2013; 25(1): 64-71.

56. Gaignier JJ, Morgenstern H, Chess L. Intervention designed to prevent anterior cruciate ligament injuries in adolescent and adults a systematic review and meta-analysis. Am J Sports Med. 2013;41 (8):1952-1962.

57. Hewett TE, Ford KR, Hoogenboom BJ, Myer GD. Understanding and preventing acl injuries: current biomechanical and epidemiologic considerations - update 2010. N Am J Sports Phys Ther. 2010;5(4):234-251.

58. Agel J, Olson D, Dick R, et al. Descriptive epidemiology of collegiate women's basketball injuries: national collegiate athletic association injury surveillance system, 1988-1989 through 2003-2004. J Athl Train. 2007;42:202-210.

59. Dempsey AR, Lloyd DG, Elliott BC, et al. Changing sidestep cutting technique reduces knee valgus loading. Am J Sports Med. 2009;37:2194-2200.

60. Cochrane JL, Lloyd DG, Besier TF, et al. Training affects knee kinematics and kinetics in cutting maneuvers in sport. Med Sci Sports Exerc. 2010;42:1535-1544.

61. Di Stefano LJ, Blackburn JT, Marshall SW, et al. Effects of an age-specific anterior cruciate ligament injury prevention program on lower extremity biomechanics in children. Am J Sports Med. 2011;39:949-957.

62. Donnelly CJ, Elliott BC, Doyle TL, et al. Changes in knee joint biomechanics following balance and technique training and a season of Australian football. Br J Sports Med. 2012;46:91722.

63. Hewett TE, Myer GD, Ford KR, et al. Biomechanical measures of neuromuscular control and valgus loading of the knee predict anterior cruciate ligament injury risk in female athletes: a prospective study. Am J Sports Med. 2005;33(4):492-501.

64. Zebis MK, Bencke J, Andersen LL, et al. The effects of neuromuscular training on knee joint motor control during side cutting in female elite soccer and handball players. Clin J Sport Med. 2008;18:329-337.

65. Wilderman DR, Ross SE, Padua DA. Thigh muscle activity, 
knee motion, and impact force during side-step pivoting in agility-trained female basketball players. J Athl Train. 2009; 44:14-25.

66. Cochrane JL, Lloyd DG, Besier TF, et al. Training affects knee kinematics and kinetics in cutting maneuvers in sport. Med Sci Sports Exerc. 2010;42:1535-1544.

67. Alentorn-Geli E, Mendiguchía J, Samuelsson K, et al. Prevention of anterior cruciate ligament injuries in sports. Part I: systematic review of risk factors in maleathletes. Knee Surg Sports Traumatol Arthrosc. 2014;22(1):3-15.

68. Alentorn-Geli E, Mendiguchía J, Samuelsson K, et al. Prevention of noncontact anterior cruciate ligament injuries in sports. Part II: systematic review of the effectiveness of prevention programmes in male athletes. Knee Surg Sports Traumato Arthrosc. 2014;22(1):16-25.

69. Michaelidis M, Koumantakis GA. Effects of knee injury primary prevention programs on anterior cruciate ligament injury rates in female athletes in different sports: a systematic review.
Phys Ther Sport. 2014;15(3):200-210.

70. Van Mechelen DM, van Mechelen W, Verhagen EA. Sport injury prevention in your pocket? Prevention apps assessed against the available scientific evidence: a review. Br J Sports Med. 2014;48(11):878-882.

71. Wojtys EM, Kothari SU, Huston LJ. Anterior cruciate ligament functional brace use in sports. Am J Sports Med. 1996;24(4): 539-546.

72. McDevitt ER, Taylor DC, Miller MD, et al. Functional bracing after anterior cruciate ligament reconstruction: a prospective, randomized, multicenter study. Am J Sports Med. 2004 32(8):1887-1892.

73. Wu G, Siegler S, Allard P, et al. Standardization and Terminology Committee of the International Society of Biomechanics; International Society of Biomechanics. ISB recommendation on definitions of joint coordinate system of various joints for the reporting of human joint motion - part I: ankle, hip, and spine. J Biomech. 2002;35(4):543-548. 